\title{
UM BREVE PENSAR SOBRE O RACISMO NO BRASIL
}

\section{A brief thinking about racism in Brazil}

\author{
Jeremias Pereira Pinto \\ Universidade Católica do Salvador (UCSAL). \\ Julie Lourau \\ Universidade Católica do Salvador (UCSAL).
}

Informações do artigo

Recebido em 08/10/2020

Aceito em 11/11/2020

doi>: https://doi.org/10.25247/2447-861X.2020.n251.p619-638

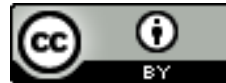

Esta obra está licenciada com uma Licença Creative Commons Atribuição 4.0 Internacional.

Como ser citado (modelo ABNT)

PINTO, Jeremias Pereira; LOURAU, Julie. Um breve pensar sobre o racismo no Brasil. Cadernos do CEAS:

Revista Crítica de Humanidades. Salvador/Recife, v. 45,

n. 250 , p. $619-638$, set./dez., 2020. DOI: https://doi.org/10.25247/2447-861X.2020.n251.p619-638

\begin{abstract}
Resumo
O texto faz uma discussão sobre a formação da população brasileira como fruto do encontro de diferentes grupos étnicos, dos povos nativos, dos europeus, dos africanos e dos imigrantes (europeus e asiáticos), pensando num país formado por matrizes culturais, diversas e distintas, ricas e complexas. Outro ponto abordado será como se organizou o ordenamento jurídico brasileiro, quais os propósitos que o conformou de tal modo a colocar as populações negra e indígena numa condição de seres humanos inferiores. É feita uma discussão sobre o processo de resistência, dando ênfase ao século $X X$, que se contrapõe ao pensamento racista, à ideia de que vivíamos numa democracia racial, assim como os movimentos que surgiram em contraponto à condição a que foram submetidos os negros. Por fim, serão apresentadas as ações efetivas para reparar as injustiças praticadas contra o povo, denominadas ações afirmativas, a exemplo da Lei 10.639/2003 e do Estatuto da Igualdade Racial/2010, que busca, de modo efetivo, resgatar a história da cultura afro no Brasil, garantindolhe os direitos, negados durante mais de quatro séculos.
\end{abstract}

Palavras-Chave: Racismo. Políticas Públicas. Igualdade Racial. Diversidade. Negros.

\section{Abstract}

The text makes a discussion about the formation of the Brazilian society as a result of the encounter of different ethnic groups, of the native people, the Europeans, the Africans and the immigrants (European and Asian), thinking about a country formed by diverse, distinct, rich and complex cultural matrices. Another point addressed is how the Brazilian juridical order was organized, what purposes constructed it in such way as to place the black and the indigenous population in a condition of inferior human beings. A discussion is made about the process of resistance, giving emphasis in the 2oth century, that opposes racist thinking, the idea that we lived in a racial democracy, as well as the movements that arose in counterpoint the condition which black people were submitted. Lastly, will be presented the effective actions to repair the injustices practiced against the people, denominated affirmative actions, such as the Law $10.639 / 2003$ and the Statute of Racial Equality/2010, which seeks, in an effective manner, to rescue the Afro culture in Brazil, granting them the rights denied for over four hundred centuries.

Keywords: Racism. Public Policies. Racial Equality. Diversity. Black people. 


\section{Introdução}

Temos o entendimento de que a população brasileira é fruto do encontro de diferentes grupos étnicos. A esse respeito, podemos citar a diversidade dos povos nativos que aqui já estavam antes da "descoberta", os europeus, que foram, no primeiro momento, os colonizadores; durante os séculos XIX e XX, os migrantes; os africanos de diversas origens étnicas que foram arrancados de suas terras, vendidos como mercadoria e transformados em escravos e, por fim, outros grupos de imigrantes da Ásia. Ou seja, pensar no País é lembrar que fomos formados por essas matrizes culturais, diversas e distintas, mas bastante ricas e complexas. A sociedade brasileira teve nos portugueses os empreiteiros responsáveis por, a princípio, dirigir a estrutura do país (SODRÉ, 2005) e dos demais segmentos étnicos, uma vasta contribuição por ora menos reconhecida.

Importantes para a formação da cultura nacional, os nativos (indígenas), os africanos e afrodescendentes tiveram, e têm até hoje, pouco destaque, sendo relegados ao segundo plano quanto ao seu reconhecimento e à sua importância na sociedade brasileira. Trazendo a atenção para a população negra, verifica-se que foram criados mecanismos que os posicionam em uma situação hierárquica inferior, no plano econômico, social e cultural, além de estigmas que disseminam esta suposta inferioridade, trazida inicialmente pela "democracia racial" e cristalizada pelo mito da democracia racial, que, após discussão e embates do movimento negro, cai por terra.

É sabido que, durante o processo escravista, mesmo sob "os chicotes" do sistema e suas intervenções sangrentas, aliado às tentativas de cooptação ideológicas por parte das classes dominantes, a população negra mantinha formas de organização paralelas de vida em comunidade para garantir a preservação de aspectos da sua cultura de origem, ao mesmo tempo em que enriquecia o caldeirão cultural.

Para Sodré (2005), essas formas paralelas de organização consubstanciavam-se, desde caixas de poupança para compra de alforrias de escravos urbanos, passando por conselhos deliberativos, particularmente para preparação de ações coletivas, como fugas e revoltas, a confrarias de assistência mútua sob a capa religiosa cristã e diretamente com o espaço dos quintais e terreiros na manutenção dos cultos aos orixás e das línguas africanas que identificam as religiões que possuem essas matrizes. 
Considerando esse cenário, este artigo tem a pretensão de promover uma discussão acerca do Estatuto da Igualdade Racial, da Lei 10.639/2003 de ensino da história e cultura afro-brasileira e indígena e dos Direitos Fundamentais previstos na Constituição Brasileira de 1988, que, no Art. $3^{\circ}$, cap. IV, tem como premissa promover o bem de todos, sem preconceitos de origem, raça, sexo, cor, idade e quaisquer outras formas de discriminação (BRASIL, 1988), levando, assim, em consideração a importância e as contribuições da população negra na formação da sociedade brasileira.

Para o desenvolvimento da pesquisa e produção do artigo, foram utilizadas as análises bibliográfica e documental.

\section{Antecedentes do estatuto da igualdade racial}

Antes de nos inserirmos nas discussões sobre Estatuto da Igualdade Racial, será importante pensar como, ao longo da história colonial e início da República, o ordenamento jurídico brasileiro serviu para propósitos "civilizatórios" e criação autoritária do Estado português que conformou a sociedade brasileira de tal modo e colocou as populações negra e indígena numa condição de seres humanos inferiores (MUNANGA, 2008).

São Bernardo (2005, p. 2), quando das discussões sobre a Ética da Diferença e Criminalização Racial, faz referência à forma violenta como se deu o processo de modernidade nas Américas, denominando-o de "grotesca violência material e simbólica esculpida no mito sacrificial de outros povos não reconhecidos e, portanto, idealizados no espelho (irracional) de si mesmo". Ele também chama a atenção, a partir da obra de Dussel, O encobrimento do outro, sobre a construção cultural induzida pela "modernidade". Essa construção tem como elementos centrais os valores europeus decorrentes de uma série de eventos importantes na Europa, tais como a Reforma Protestante, a llustração e a Revolução Francesa, que foram colocados como valores universais e resultado do processo civilizatório na sua forma bem sucedida. Nas lógicas que carregam essa construção cultural, tudo que não é si mesmo é um outro marcado pelo negativo: a "culpa", a "preguiça", a "covardia" e a "involução civilizatória" são atributos pensados enquanto inatos e estariam fadados inexoravelmente aos latinos, asiáticos e africanos. Essas são as teses defendidas pelas teorias raciais que ocuparam bastante os cientistas desde a segunda metade do século XIX até a Segunda Guerra Mundial. 
Dessa forma, dentro da posição de inferioridade, trazida pela Modernidade estabelecida como divisor de águas no processo civilizatório do mundo, em que são colocados os grupos referenciados (os latinos, os asiáticos e os africanos), é importante analisar o contexto geral em que foram colocados negros escravizados pelos portugueses e indígenas no Brasil. São Bernardo afirma que:

Os portugueses são pioneiros na expansão marítima e são aqueles que primeiro nos impuseram a idéia de dominação mundial calcada no controle da natureza e do humano fundados no triunfo da razão e de uma fé racionalizada. Mais tarde, com as teses iluministas, a análise por princípio, o experimentalismo e as verdades das ciências serão os elementos que orientarão a decadência de uma modernidade que exalta e mata o sujeito. Havia uma dúvida fundamental nos lluministas: como conjugar uma certa tolerância - endeusada como uma das mais caras virtudes à diversidade da natureza humana - com a atitude subjugadora das diversidades sociais de homens e mulheres oriundas de distintos mundos da vida. (SÃO BERNARDO, 2005, p. 2).

Assim, foi à base de domínio português que se organizou o Estado brasileiro, definindo suas estruturas para o funcionamento da burocracia e da base jurídica, tendo como parâmetro a Formação do Estado Moderno, a partir do século XIV, e que tinha como pontos base a centralização e concentração das Forças Armadas e do monopólio da violência, da estrutura jurídica e da cobrança de impostos, além de um corpo burocrático para administrar o patrimônio público.

Utilizando-se dessa base estrutural do Estado Moderno, a Coroa Portuguesa, o Estado português no Brasil, definiu as bases jurídicas e burocráticas do funcionamento da justiça, objetivando manter a imparcialidade e a honestidade. A Coroa portuguesa, em 1600, buscou manter um isolamento aos magistrados no reino, de modo que estes não se intrometessem nos negócios e nas relações sociais, mas não conseguiu estabelecer esse isolamento, pois os desembargadores aderiram à condição de donos de escravos, tendo, inclusive, alguns deles se inserido no tráfico escravagista (SÃO BERNADO, 2005).

Para controlar o que a Coroa denominava de desordem pública, foram estabelecidas determinações judiciais através da Lei de 20 de outubro de 1735, que, na verdade, regulava comportamentos e condutas da população não europeia. O estabelecimento dessa lei é resultado de um pensamento positivista, evolucionista e frenológico, que introduz no estado brasileiro o ideário de ordem e progresso, o que, para a Coroa, justificava e naturalizava as 
diferenças entre os indivíduos. As ações jurídicas adotadas pelo aparato estatal são um exemplo de que, desde sempre, houve "dificuldades" em reconhecer as populações negra e indígena enquanto integrantes da sociedade brasileira, o que permanece por vários séculos, conforme pode ser constatado nas afirmações de São Bernado (2005):

O tratamento do Estado imperial dado aos africanos e seus descendentes no Brasil do final do século XIX e início o século XX proporcionaram explicações e atitudes, as mais incomuns, para a formulação do ordenamento jurídico do Império e em especial da legislação penal e, com ele, variáveis tipificações criminais das manifestações sociais, culturais e religiosas dos grupos africanos, então trazidos por ocasião do colonialismo e do escravismo europeu nas Américas. (SÃO BERNARDO, 2005, p. 3).

Durante o império, a criação da legislação criminal visava obter um maior controle social sobre os escravos, de tal modo que foram instituídas várias tipificações, válidas exclusivamente para os negros escravizados. São Bernardo (2005), em análise dos artigos do Código Criminal do Império, nos mostra como era fácil depreender que o que se pretendia era criminalizar os negros em razão de suas manifestações culturais e religiosas:

Art. 276. Celebrar em casa, ou edifício, que tenha alguma forma exterior de templo, ou publicamente em qualquer lugar, o culto de outra religião, que não seja a do Estado.

Penas - de serem dispersos pelo Juiz de Paz os que estiverem reunidos para o culto; da demolição da forma exterior; e de multas de dois a doze mil réis, que pagará cada um.

Art. 280 - Praticar ação, que na opinião pública, seja considerada ofensiva da moral e dos bons costumes.

Art. 295. Não tomar qualquer pessoa uma ocupação honesta e útil, de que possa subsistir, depois de advertido pelo Juiz de paz, não tendo renda suficiente.

Pena de prisão com trabalho de 8 a 24 dias. P. 117 (SÃO BERNARDO, 2005, p. 6-7).

Com os embates acontecendo ao longo dos séculos, não podemos esquecer de destacar a resistência das nações africanas contra a dominação imposta pelos colonizadores, como destaca São Bernardo (2005, p. 5-6): "A tradição oral e uma certa antropologia corporal orientaram os pressupostos dessa resistência que continuou a ser enfrentada de modo subliminar pela inteligência conservadora da então República velha brasileira". 
Partindo da então muito falada teoria da degenerescência das raças do Comte de Gobineau, que tinha a mestiçagem como principal fator, os intelectuais da escola de Recife improvisaram uma resposta para salvar o país (o Nordeste já é bastante miscigenado) deste funeste destino premeditado pelos homens de ciência europeus. Eles inventaram um modo de reverter as conclusões dessa teoria, para neutralizar os efeitos degenerativos. É assim que Silvio Romero, coterrâneo de Gilberto Freyre, afirma que a misceginação à brasileira é um elemento a ser tomado em conta de modo favorável e até mesmo a ser destacado como "composição étnica e anthropológica singular": "Formamos um paiz mestiço... somos mestiços se não no sangue ao menos na alma". (ROMERO, 1888, apud SCHWARCZ, 1994, p. 137). A mestiçagem se torna, então, uma especificidade brasileira. Este pensamento é fundamental para a construção da democracia racial enquanto mito fundador da identidade brasileira nesta jovem República que ainda tem dificuldade para se pensar em termos de igualdade.

Entretanto, no Brasil, nesse período, duas áreas e escolas distintas, a de Medicina, representada pelas da Bahia e do Rio de Janeiro, e as de Direito, em Olinda e São Paulo, se destacam no apoio às teorias racistas, influenciadas por estudiosos estrangeiros e brasileiros. A esse respeito, Schwarcz (1994) cita alguns cientistas estrangeiros acerca de como era considerada negativa a miscigenação no Brasil, a exemplo de Louis Agassiz, do Conde Arthur de Gobineau e do naturalista Gustave Aimard (viajante francês), do brasileiro João Batista Lacerda, na época diretor do Museu Nacional.

Apesar de a discussão envolver os "homens da ciência", das escolas de Medicina da Bahia e do Rio de Janeiro, iremos nos ater apenas em analisar as escolas de Direito do Recife e São Paulo.

A criação das faculdades de Direito de Olinda e de São Paulo foi importante na medida em que, ainda sobre o domínio português, estas tentam se desvincular da metrópole através da criação de uma constituição brasileira, elaborada por uma elite formada por pessoas letradas. Entretanto, a principal questão está aqui colocada por Schwarcz (1994. p. 141): "Para os homens de direito a responsabilidade de conduzir a nação estava vinculada à elaboração de um código unificado, que tornasse homogêneas as grandes diferenças observáveis".

As diferenças observadas pela referida autora eram as seguintes: a faculdade de São Paulo tinha um padrão com base no modelo político liberal, enquanto que a do Recife tinha 
uma linha voltada às questões raciais, determinando, assim, que a faculdade de Pernambuco estivesse mais voltada para a formação de cientistas, pois nela se realizava um curso de Antropologia Criminal; a de São Paulo estava voltada para a formação política e de burocratas, já que tinha curso na área de Direito Civil.

Schwarcz (1994, p. 142) afirma que, mesmo existindo diferenças entre as duas escolas, as coincidências no pensar se faziam presentes, haja vista que, quando defendiam a hegemonia da prática do Direito, a garantia de uma hierarquia social, e assim, "[...] o argumento escorregava da cultura para a natureza, do indivíduo para o grupo, da cidadania para a raça". E conclui a análise das escolas de Direito deixando bem clara a forma como elas se posicionavam nas discussões que envolvem raça e cidadania. Afirma Schwarcz (1994):

Dessa maneira, enquanto na Escola de Recife um modelo claramente determinista dominava, em São Paulo um liberalismo de fachada - cartão de visitas para questões de cunho oficial -, convivia com um discurso racial, prontamente acionado quando se tratava de defender hierarquias, explicar desigualdades sociais. A teoria racial, quando utilizada, cumpria o papel de deixar claro como para esses juristas falar em democracia não significava discorrer sobre a noção de cidadania. Assim, se em Recife o indivíduo foi sempre entendido como uma amostra de seu grupo; em São Paulo, com a adoção de um liberalismo de cunho conservador e cada vez mais antidemocrático, a questão da cidadania como que desaparecia e com ela a vontade do indivíduo. Como dizia uma artigo publicado em 1914 na revista da escola paulista, 'o indivíduo no Brasil sempre foi letra mortal... e afinal, quem se importa'. (SCHWARCZ, 1994, p. 142).

Vê-se, assim, que houve um embate, apenas na forma de pensar o racismo, mas não no conteúdo, entre as escolas de Direito e de Medicina, em que se reproduzem as teorias racistas predominantes nessa época e que colocavam a miscigenação como elemento negativo.

Dentre as teorias que foram motivo desses embates, não podemos deixar de fora a questão levantada, tendo como ponto de partida a ideia extraída do pensamento Freyre de que vivíamos em uma democracia racial. Muito dessa construção é atribuída à influência de Franz Boas, antropólogo norte americano com quem estudou durante alguns anos no estado de Columbia-EUA. No entendimento de Freyre, conforme registrado em sua principal obra Casa Grande \& Senzala, lançada em 1933 (FREYRE, 2001), existe uma grande interação entre o senhor de engenho e os escravos. Embora não tenha afirmado categoricamente isso, existe um entendimento de que ele levantava a ideia de uma democracia racial, assim, ao mesmo 
tempo em que se distancia do racismo preponderanete no século $X X$, também teria admitido que diversas culturas influenciaram na formação da socieadade brasileira, criando uma imagem que seria idílica do Brasil colonial (SILVA, 2015).

Analisando as questões pontuadas sobre o "mito da democracia", Pinto e Silva (2019) afirmam que:

\begin{abstract}
depois de muitos anos de debates, discordâncias, resistências por parte dos movimentos sociais, tendo como ponta de lança os movimentos negros, as discussões levam à derrubada do mito da democracia racial, ou seja, a ideia de que vivemos em uma harmonia entre as pessoas, da não existência do racismo, das mesmas oportunidades para todos, independentee da cor da pele. Na verdade, premissas incompatíveis com a realidade vivida e observada contidianemente, verdades que podem ser entendidas como tentativas de encobrir os debates sobre a desigualdade racial e o perverso resultado da escravidão de mais de 300 anos no Brasil. (PINTO; SILVA, 2019, p. 5).
\end{abstract}

\title{
A resistência do Movimento Negro
}

Neste tópico, faremos uma discussão acerca do processo de resistência, ao longo do século $X X$, em contraponto à predominância do pensamento racista e à subjugação a que os negros escravizados foram submetidos. Portanto, será impotante rememorar os vários movimentos que surgiram em contraponto à opressão que os negros escravizados sofreram, durante quatro séculos, durante a escravidão em toda América Latina. Vale ressaltar que o Brasil foi o último país do ocidente a abolir oficialmente a escravidão (MALOMALO; LOURAU; SOUZA, 2018).

Fazendo uma retrospectiva da luta contra o processo de dominação no âmbito mundial, praticada pelos países do Norte, foi realizada a Conferência de Bandung em 1955, que reuniu 29 países africanos e 42 asiáticos, na resistência contra a dominação e influência negativa dos países ricos, colocando a prática do racismo como crime, o que foi protalmente abafado pelos "dominantes". Esse foi considerado um dos grandes movimentos de resistência, do século XX, assim colocado por Malomalo, Lourau, Souza (2018), como:

Ela foi e é considerada, até hoje, um marco no despertar dos governos, até então dominados economicamente pelo Norte. Estes países passaram a agir coletivamente na política internacional, defendendo uma agenda própria e totalmente diferente daquela que era subordinada pelos países dominantes. (MALOMALO; LOURAU; SOUZA, 2018, p. 521). 
Complementando o destaque que foi dado à conferência, Leite (2011) destaca alguns dos principais pontos que nortearam a Conferência:

[...] o respeito aos direitos humanos fundamentais e aos propósitos e princípios da Carta das Nações Unidas; respeito à soberania e à integridade territorial de todas as nações; reconhecimento da igualdade de todas as raças e de todas as nações, grandes ou pequenas; promoção de interesses mútuos e da cooperação; respeito à justiça e às obrigações internacionais. (LEITE, 2011, p. 56).

Pensando em termos de Brasil, o processo ganha novo fôlego a partir da segunda metade do século XX. Nas décadas de 1960/1970, o Movimento Negro estabelece a luta contra o racismo. Destacam-se como integrantes da Constituinte de 1988 nomes tais como Abdias do Nascimento e Carlos Alberto Caó, através da aprovação de alguns Artigos da Constituição, tipificando o racismo como crime, assumindo o Brasil como uma nação multicultural. Na celebração de aniversário de morte de Zumbi, em 1995, uma grande marcha exigiu que o Governo Federal, na época presidido por Fernando Henrique Cardoso, reconhecesse a existência do racismo estrutural, resultando na criação de um Grupo de Trabalho Interministerial, que visava ao desenvolvimento de políticas que valorizassem a população negra, resultando na implantação de políticas de cotas raciais no estado do Rio de Janeiro. Nos anos 2000, Fernando Henrique Cardoso apoia financeiramente a ida de uma delegação para a Conferência de Durban (África do Sul) (MALOMALO; LOURAU; SOUZA, 2018). Vale ressaltar que estava na pauta da I Conferência Mundial: a luta contra o Racismo, a Discriminação Racial, a Xenofobia e as Formas Conexas de Intolerância.

No ano de 2000, é implementado um sistema de cotas, pelo governo do estado do Rio de Janeiro, a Lei no 3.524 , o qual estabelece $50 \%$ das vagas oferecidas pelas universidades públicas estaduais seriam destinadas a estudantes que cursaram integralmente os ensinos fundamental e médio nas redes públicas municipais e/ou do estado. Ainda no estado do Rio de Janeiro, em 2001, a Lei n 3.798 , assegura $40 \%$ das vagas para a população negra e parda nos cursos de graduação da Universidade do Estado do Rio de Janeiro e da Universidade Estadual do Norte Fluminense. (MALOMALO; LOURAU; SOUZA, 2018). No Estado da Bahia, em 2002, se implementa a política de acesso via cotas raciais e sociais para ingresso na Universidade Estadual da Bahia. Entre 2003 e 2007, no governo do então presidente Lula, é criada a Secretaria Nacional de Políticas de Promoção da Igualdade Racial (SEPPIR), 
considerada como um marco nas políticas relacionadas às questões raciais, além disso, é promulgada a Lei 10.639/2003 e o Estatuto da Igualdade Racial, que serão discutidos no seguimento deste trabalho.

\section{As ações afrimativas, a Lei 10.639: a luta pelo reconhecimento às diferenças}

Considerando o ponto de vista legal, verifica-se que os ordenamentos jurídicos voltados às questões étnico-raciais no Brasil não são recentes, pois datam da década de 1950, via a Lei Afonso Arinos, de 3 de julho de 1951 (BRASIL, 1951) que proíbe a discriminação racial no Brasil e prevê igualdade de tratamento e de direitos para todos.

Na Constituição Federal de 1988 (BRASIL, 1988), em seu artigo terceiro, inciso IV, há a garantia de igualdade a todos os cidadãos, sem preconceito de origem, raça, sexo e qualquer outra forma de discriminação. Além disso, segundo a Constituição Federal, em seu artigo 242, parágrafo $1^{\circ}$, estabelece que "O ensino da História do Brasil levará em conta as contribuições das diferentes culturas e etnias para a formação do povo brasileiro". (BRASIL, 1988).

A partir dos anos 2000, com a implantação e implementação das Políticas de Ações Afirmativas, podemos perceber que algumas mudanças são efetivas. A Lei 10.639 de og de janeiro de 2003 (BRASIL, 2003) é considerada um marco, visto que designa que, nas instituições educacionais, seja inserido o estudo da história e cultura da África e dos africanos, a luta dos negros no Brasil, a cultura negra brasileira e o protagonismo negro na formação da sociedade nacional, de modo a resgatar sua contribuição na área social, econômica e política, pertinentes à História do Brasil. A Lei citada torna obrigatória, no currículo oficial da Rede Básica de Ensino (Fundamental e Médio), a temática História e Cultura Afro-brasileira e dá outras providências (BRASIL, 2006).

A inserção, no calendário letivo, do dia 20 de novembro como "Dia Nacional da Consciência Negra" é outro momento relevante, pois esse dia marca a morte/desaparecimento do mais representativo líder da resistência contra a escravidão, Zumbi, e do Quilombo de Palmares, seu maior foco de luta contra a exploração sofrida pelos negros no Brasil (BRASIL, 2011).

A fomentação da Lei 10.639/2003 foi importante, também, na medida em que se intensificam as reivindicações dos direitos até então invisíveis no país para as populações 
negra e indígena, bem como na necessidade de capacitar os profissionais da educação para se efetivar a lei.

Assim, as políticas de ações afirmativas de reconhecimento e valorização da cultura e identidade buscam combater o racismo, propõem a divulgação e produção de conhecimentos, a formação de atitudes, posturas e valores que eduquem cidadãos orgulhosos de seu pertencimento étnico-racial, os descendentes de africanos, os povos indígenas, os descendentes de europeus, de asiáticos, para que interajam na construção de uma nação democrática, em que todos, igualmente, tenham seus direitos garantidos e sua identidade valorizada (BRASIL, 2004).

Diante das novas possibilidades trazidas pelas ações afirmativas, podemos afirmar que a promoção de uma educação multicultural requer uma série de mudanças, que passa por uma ampla reforma educacional, objetivando a criação de oportunidades que vislumbrem o sucesso escolar para todos os alunos, independentemente de seu agrupamento étnico/racial, já que, num mundo global, não se admitem mais políticas de exclusão, e sim, de respeito às diferenças, à diversidade, no que tange às questões étnicas, religiosas, de identidade de gênero, cultural, entre outros.

\section{O Estatuto da igualdade racial: a luta pela igualdade ampliada}

Fruto de um longo processo histórico de lutas pela reparação das injustiças cometidas pelos colonizadores contra os negros que foram escravizados no continente americano, em específico no Brasil, que perdurou por quase 400 anos, foi instituído, pela Lei $n^{\circ} 12.288$, de 20 de Julho de 2010, o Estatuto da Igualdade Racial. Para Santos (2010), o dia 20 de outubro de 2010 foi marcado por um acontecimento ímpar na história brasileira, mas, logo em seguida, afirma que:

O Estatuto da Igualdade Racial, do ponto de vista histórico, nada mais é que o terceiro artigo que faltou à Lei Imperial no 3.353, de 1888, que "aboliu" a escravidão no Brasil, a qual, com um pouco de criatividade e uma boa técnica legislativa, poderia ter inclú́do o artigo $1^{\circ}$ da Lei $n^{\circ} 12.288$, de 2010, à Lei Imperial n 3.353 , de 1888 , sem provocar nenhuma incongruência. Com essa suposta modificação a Lei da Abolição teria a seguinte redação:

Lei Imperial nº 3.353, de 1888, modificada pela Lei 12.288, de 2010

Declara extinta a escravidão no Brasil e institui o Estatuto da Igualdade Racial. Art. 1. ${ }^{\circ}$ É declarada extinta desde a data desta lei a escravidão no Brasil. 
Art. 2..$^{\circ}$ Esta Lei institui o Estatuto da Igualdade Racial, destinado a garantir à população negra a efetivação da igualdade de oportunidades, a defesa dos direitos étnicos individuais, coletivos e difusos e o combate à discriminação e às demais formas de intolerância étnica.

Art. 3. ${ }^{\circ}$ : Revogam-se as disposições em contrário. (SANTOS, 2010, p. 1).

No seu Art. $1^{\circ}$, o Estatuto está destinado a garantir à população negra a efetivação da igualdade de oportunidades, a defesa dos direitos étnicos individuais, coletivos e difusos e o combate à discriminação e às demais formas de intolerância étnica.

Como forma de efetivar os direitos da população negra, podemos pensar como o Estatuto da Igualdade vai lidar com elementos fundamentais para reparar a injustiça praticada ao longo dos séculos, período em que os anseios dessa população ficaram encobertos pelo não reconhecimento como integrantes de uma sociedade multirracial.

Na saúde, estabelece a criação da Política Nacional de Saúde Integral da População Negra, assim como ter representantes do movimento negro nos conselhos de controle social da área, objetivando o acesso universal e igualitário ao Sistema Único de Saúde (SUS), visando promover, proteger e recuperar a saúde da população negra.

Na educação, vai reforçar a Lei que trata do Ensino da História Geral da África e história da população negra, a 10.639/2003, nas escolas de ensino fundamental, de ensino médio, sejam eles públicos e privados, assim como fomentar a formação inicial e continuada de professores e de uma política, com objetivo de elaborar material didático específico. Também estabelece cotas para ingresso nas Instituições de Ensino Superior, ampliando o acesso da população negra ao ensino gratuito, que fomentem a pesquisa e pós-graduação, com incentivos a programas voltados para temas referentes às relações étnicas, aos quilombolas e às questões pertinentes à população negra.

No que se refere ao direito à cultura, ao esporte e ao lazer, é reconhecida a existência de um patrimônio histórico e cultural, inerente às sociedades negras, também os clubes, além de outras formas de manifestação no contexto coletivo da população negra, pois nela existe uma trajetória histórica comprovada. É assegurado aos remanescentes dos quilombolas, o direito a preservar seus usos, costumes, tradições, assim como às manifestações religiosas, incentivando celebrar suas personalidades e datas comemorativas, ligadas à história do samba, além de outras manifestações culturais de matriz africana, a exemplo da capoeira, que, depois do Estatuto, torna-se um desporto de criação nacional, podendo ser ensinada, 
em instituições de cunho público e/ou privadas, por capoeiristas ou mestres tradicionais, reconhecidos dentro das formalidades.

No que trata do direito à liberdade de consciência e de crença, garante a total liberdade de consciência e de crença, assim como assegura o exercício dos cultos religiosos de matriz africana, protegendo os locais de culto e liturgia, liberando a divulgação, via o acesso aos órgãos e aos meios de comunicação.

Outro ponto que está assegurado pelo Estatuto é o acesso a terra, uma vez que outorga aos poderes públicos o desenvolvimento de políticas públicas para o acesso da população negra a terra e atividades de produção, possibilita, amplia e simplifica as possibilidades de fazer financiamentos agrícolas, garante apoio no que se refere à assistência técnica, orientação e educação profissional, além de fortalecer a logística para comercializar os produtos, para desenvolver, de forma sustentável, os espaços dos remanescentes de quilombos, com vistas a proteger ambientalmente as comunidades, possibilitando a obtenção dos títulos de propriedade.

O Estatuto assegura o acesso à moradia adequada para a população negra que viva em áreas sem condições adequadas, a exemplo de favelas, cortiços, áreas urbanas subutilizadas, em processo de degradação ou efetivamente degradadas, garantindo-lhes infraestrutura e equipamentos de uso coletivo, assim como assistência jurídica e técnica que Ihes possibilitem reformar ou regularização fundiária quando a habitação estiver em área urbana.

Outros pontos que estão previstos no Estatuto são os que tratam da igualdade de oportunidades no trabalho, dos meios de comunicação, do acesso à justiça e à segurança, do financiamento da promoção da igualdade racial. Fazendo uma análise em conjunto de todos estes, vamos perceber que são anseios historicamente reivindicados pela população negra e, até então, não contemplados. Na verdade, são materializados na sociedade na forma de exclusão social, como nos indicados pelos índices de desempregados do país, que mostram que a maioria da população negra ou está desempregada ou encontra-se na parte mais baixa da pirâmide das ocupações profissionais, segundo dados do IBGE publicados em 2019. Na mídia, verifica-se que é pouco representativa a participação dos profissionais negros (atores, jornalistas) nas propagandas, na televisão ou no cinema, e, quando se fazem presentes, estão colocados em papéis secundários, quase invisíveis ou marginalizados. 
$\mathrm{Na}$ área da justiça e da segurança pública, verifica-se que a população prisional das penitenciárias do país tem cor, já que, em sua grande maioria, ela é composta por negros, o que equivale dizer que, no processo de exclusão, essa população sofre até hoje a estigmatização de que todos são marginais.

Por fim, o Estatuto da Igualdade racial foi criado para combater as desigualdades alimentadas pelo preconceito racial, adotando medidas de promoção da igualdade em áreas de suma importância para a população negra, como na educação, na saúde, na geração de emprego e renda, no desenvolvimento agrário, na habitação popular, no desenvolvimento regional, na cultura, no esporte e lazer. Ressaltamos sua importância, pois, por cascata, torna obrigatórias ações mais efetivas de inclusão das políticas afirmativas nos programas, nos planos plurianuais, sendo esperado um aumento nos orçamentos anuais da União, dos Estados e municípios.

Para que seja melhor entendido o clamor dos movimentos de luta contra o racismo ao longo de mais de um século pós abolição da escravatura, nasce o Estatuto da Igualdade Racial, convergindo, assim, com o pensamento de Piovesan, na evidente necessidade de se obter a igualdade entre os colocados como desiguais:

Faz-se necessário combinar a proibição da discriminação com políticas compensatórias que acelerem a igualdade enquanto processo. Isto é, para assegurar a igualdade não basta apenas proibir a discriminação, mediante legislação repressiva. São essenciais as estratégias promocionais capazes de estimular a inserção e inclusão de grupos socialmente vulneráveis nos espaços sociais. Com efeito, a igualdade e a discriminação pairam sob o binômio inclusão-exclusão. Enquanto a igualdade pressupõe formas de inclusão social, a discriminação implica a violenta exclusão e a intolerância à diferença e à diversidade. O que se percebe é que a proibição da exclusão, em si mesma, não resulta automaticamente na inclusão. Logo, não é suficiente proibir a exclusão, quando o que se pretende é garantir a igualdade de fato, com a efetiva inclusão social de grupos que sofreram e sofrem um consistente padrão de violência e discriminação. (PIOVESAN, 2005, p. 40).

Ainda, para complementar, afirma que:

Neste sentido, como poderoso instrumento de inclusão social, situam-se as ações afirmativas. Estas ações constituem medidas especiais e temporárias que, buscando remediar um passado discriminatório, objetivam acelerar o processo de igualdade, com o alcance da igualdade substantiva por parte de grupos vulneráveis, como as minorias étnicas e raciais, as mulheres, dentre outros grupos. 
As ações afirmativas, enquanto políticas compensatórias adotadas para aliviar e remediar as condições resultantes de um passado discriminatório, cumprem uma finalidade pública decisiva para o projeto democrático, que é a de assegurar a diversidade e a pluralidade social. Constituem medidas concretas que viabilizam o direito à igualdade, com a crença de que a igualdade deve se moldar no respeito à diferença e à diversidade. Através delas transita-se da igualdade formal para a igualdade material e substantiva. (PIOVESAN, 2005, p. 40).

Assim sendo, podemos pensar como a implantação do Estatuto da Igualdade Racial vai convergir com pontos da Constituição Federal de 1988, no Art $5^{\circ}$. Seguem alguns pontos que podemos considerar, além de outros não citados, mas que se inserem e podem ser parâmetros das discussões apresentadas:

I - homens e mulheres são iguais em direitos e obrigações, nos termos desta Constituição;

II - ninguém será obrigado a fazer ou deixar de fazer alguma coisa senão em virtude de lei;

III - ninguém será submetido a tortura nem a tratamento desumano ou degradante;

IV - é livre a manifestação do pensamento, sendo vedado o anonimato;

$\mathrm{V}$ - é assegurado o direito de resposta, proporcional ao agravo, além da indenização por dano material, moral ou à imagem;

VI - é inviolável a liberdade de consciência e de crença, sendo assegurado o livre exercício dos cultos religiosos e garantida, na forma da lei, a proteção aos locais de culto e a suas liturgias;

VII - é assegurada, nos termos da lei, a prestação de assistência religiosa nas entidades civis e militares de internação coletiva. (BRASIL, 1988, sem paginação).

Vale ressaltar que esses são alguns pontos destacados para demonstrar como a Constituição Federal do Brasil, estabelecendo limites no que toca aos Direitos e Garantias fundamentais.

\section{Considerações finais}

A proposta do texto foi discutir sobre o Estatuto da Igualdade Racial no Brasil, apresentando uma análise inicial de como o racismo se entranhou durante vários séculos nos 
meandros da sociedade no Brasil, sobretudo, nos grupos que dominavam o país. Temos por base de sustentação duas das principais academias até então estabelecidas no país: as escolas de Medicina e Direito. Posterior a esse processo de dominação, foi disseminada a ideia de que havia a conivência pacífica entre os grupos étnicos aqui existentes, entendidos como uma democracia racial. Os diversos debates e embates foram importantes na luta contra a discriminação racial, negando a existência da convivência harmônica entre os grupos presentes no País, jogando por terra a ideia do "paraíso racial" e derrubando, de uma vez por todas, o mito da democracia racial.

Outo ponto destacado no texto foram os grupos que resistiram à discriminação racial, na luta constante pela adoção de políticas de inclusão dos negros na sociedade, via a implantação das políticas de ações afirmativas, na busca de outros olhares no que no que diz respeito às questões raciais.

Os espaços de resistência, articulados incialmente por processos externos e, posteriormente, internos, tendo à frente, aqui no país, o Movimento Negro e outros expoentes da luta, são os pilares que vão manter acesa a chama da luta dos negros contra todo tipo de opressão e sofrimento pelo qual passa a população negra no país. Assim, os primeiros resultados da resistência serão positivos na medida em que parlamentares negros conseguem incluir na Constituição Federal de 1988 alguns artigos de proteção, a exemplo da promoção do bem de todos, eliminando preconceitos de origem, raça, sexo, cor, idade e quaisquer outras formas de discriminação. Além disso, algumas instituições, ainda na década de 1990/2000, instituem o sistema de cotas raciais para ingresso nas universidades públicas estadual do Rio Janeiro e da Bahia, e também na prefeitura da capital do estado Fluminense. Toda a movimentação ao redor da Conferência de Durban (Terceira Conferência mundial contra o racismo, a discriminação racial, a xenofobia e as formas correlatas de intolerância) é o ponto de partida para um novo olhar do Governo Federal, ainda na gestão de Fernando Henrique Cardoso, que forma uma comissão para que políticas voltadas para a população negra sejam articuladas e implementadas.

O tensionamento exercido pelos movimentos de resistência resulta na adoção e implementação das políticas de ações afirmativas, direcionadas ao povo negro, aumentando a sua visibilidade, tanto assim que, vários deles, independentemente do gênero, passam a ser reconhecidos nacional e internacionalmente, atuando nas áreas acadêmicas de pesquisa, na formação da opinião pública, nas artes cênicas, nos grupos teatrais, como atores televisivos 
e intelectuais, que, de uma forma mais ostensiva, os colocam em um patamar diferenciando da sociedade, uma vez que eram vistos apenas como integrantes dos grupos marginalizados da sociedade, ocupando sempre funções desqualificadas, com remotas ou poucas possibilidades de atingir hierarquias superiores dentro da estrutura social. É importante ressaltar que, diante das mudanças ocorridas no cenário do Brasil, a partir de 2016, quando houve a retirada de um governo com viés democrático, para um governo conservador, o caminho torna-se mais difícil para resolver as questões voltadas ao racismo.

No que trata especificamente do Estatuto da Igualdade Racial, houve uma busca em entender como a Lei trabalha com o intuito de reparar as injustiças cometidas por quase quatro séculos de escravidão, período que, na verdade, fez do Brasil o último país a abolir esse sistema perverso, que colocou os negros trazidos nos porões dos navios negreiros em condições sempre de inferioridade na sociedade brasileira, situação que, infelizmente, perdura até os dias atuais, apesar dos avanços obtidos através das políticas de cotas raciais nas universidades, do reconhecimento da cultura e de outros aspectos até então desconsiderados.

Medidas reparatórias, como pudemos exemplificar através da Lei de Cotas, Lei 10.639/2003, e principalmente da mais abrangente, o Estatuto da Igualdade Racial, são, de fato, instrumentos jurídicos que obrigamo Governo Federal, assim como os Estados que compõem a Federação a repensarem suas políticas públicas que, durante mais de 300 anos, caracterizam-se pela inexistência/ausência de políticas que incluam e abarquem demandas do povo negro. Historicamente, houve a negação da cidadania a esse grupo, mesmo em locais como a capital do Estado da Bahia, Salvador, em que, segundo estimativas (IBGE, 2019), seus habitantes são compostos por percentuais superiores a $80 \%$ de negros.

Ainda hoje se fazem presentes na sociedade visões e posturas estigmatizantes, dotadas de preconceitos, que tentam, e, infelizmente, conseguem diminuir a visibilidade e o protagonismo dos negros que são integrantes da população brasileira. São inegáveis, mais ainda, os pequenos avanços econômicos e sociais, especificamente entre os governos menos conservadores de esquerda, entre 2003 e 2016. Mesmo nessa conjuntura democrática, a exclusão pelo viés racial se faz presente de forma perceptível nos integrantes mais pobres do País, já que a população negra não está incluída na pauta principal quando se elaboram as prioridades e as diretrizes para a melhoria de vida dos habitantes do Brasil. 
Vale ressaltar, ainda, que, durante o período colonial, a Coroa Portuguesa criou Leis para fazer valer a crença de que somos diferentes e alguns grupos, como as populações negra e indígena, foram colocados como seres inferiores, a tal ponto de lhes impor medidas rigorosas, argumentando que assim estaria mantendo a ordem.

Faz-se necessário suplantar as enormes distorções, base sobre a qual se formou a sociedade brasileira. No que se refere aos grupos étnicos, essa reparação deve ser uma das principais perspectivas, para que não se percam de vista as exclusões históricas e o peso do preconceito racial na constituição da sociedade do Brasil contemporâneo. Resistir, combater, desconstruir os ideais trazidos pelos colonizadores e dominantes de que eles são superiores em função da cor de sua pele e de sua cultura tida como superior. A disseminação de que não existe resistência e de que nos deixamos dominar facilmente foi, por vários séculos, a maneira mais eficaz de minar e enfraquecer a luta contra este grande câncer que ainda se faz presente, a ponto de se institucionalizar, enraizado na sociedade brasileira, difícil de ser extirpado, que é o racismo, mas que está sendo aos poucos descontruído pela resistência.

\section{Referências}

BRASIL. Constituição da República Federativa do Brasil de 1988. Presidência da República. Brasília: Casa Civil. Subchefia para Assuntos Jurídicos, 1988. Disponível em: http://www.planalto.gov.br/ccivil_03/constituicao/constituicaocompilado.htm. Acesso em: 06 de nov. 2018.

BRASIL. Lei nº 1.390, de 3 de julho de 1951. Lei Afonso Arinos. Inclui entre as contravenções penais a prática de atos resultantes de preconceitos de raça ou de côr. Disponível em: https://presrepublica.jusbrasil.com.br/legislacao/128801/lei-afonso-arinoslei-1390-51. Acesso em: 06 de nov. 2018.

BRASIL. Lei n 10.639, de 9 de janeiro de 2003. Altera a Lei no 9.394, de 20 de dezembro de 1996, que estabelece as diretrizes e bases da educação nacional, para incluir no currículo oficial da Rede de Ensino a obrigatoriedade da temática "História e Cultura Afro-Brasileira", e dá outras providências. Brasília: Casa Civil, 2003. Disponível em:

http://www.planalto.gov.br/ccivil_03/LEIS/2003/L10.639.htm. Acesso em: 06 de nov. 2018.

BRASIL. Lei n⿳0 12.288, de 20 de julho de 2010. Institui o Estatuto da Igualdade Racial; altera as Leis nos 7.716, de 5 de janeiro de 1989, 9.029, de 13 de abril de 1995, 7.347, de 24 de julho de 1985, e 10.778, de 24 de novembro de 2003. Brasília: Casa Civil, 2010. Disponível em: http://www.planalto.gov.br/ccivil_03/_Ato2007-2010/2010/Lei/L12288.htm. Acesso em: 01 dez. 2018. 
BRASIL. Lei n 12.519, de 10 de novembro de 2011. Institui o Dia Nacional de Zumbi e da Consciência Negra. Brasília: Casa Civil, 2011. Disponível em:

http://www.planalto.gov.br/ccivil_03/_ato2011-2014/2011/lei/l12519.htm. Acesso em: 06 de nov. 2018.

BRASIL. Orientações e Ações para Educação das Relações Étnico-Raciais. Brasília: SECAD, 2006. Disponível em:

http://portal.mec.gov.br/dmdocuments/orientacoes_etnicoraciais.pdf. Acesso em: 02 nov. 2018.

BRASIL. Parecer das Diretrizes Curriculares Nacionais para a Educação das Relações Étnico-Raciais e para o Ensino de História e Cultura Afro-Brasileira e Africana. Brasília: MEC/CNE, 2004. Disponível em: http://portal.mec.gov.br/dmdocuments/cnecp_003.pdf . Acesso em 02 nov. 2018.

FREYRE, Gilberto. Casagrande \& senzala. 42. ed. Rio de Janeiro: Record, 2001.

IBGE - INSTITUTO BRASILEIRO DE GEOGRAFIA E ESTATÍSTICA. Pretos ou pardos estão mais escolarizados, mas desigualdade em relação aos brancos permanece. Agência de Notícias, 13 nov. 2019. https://agenciadenoticias.ibge.gov.br/agencia-sala-deimprensa/2013-agencia-de-noticias/releases/25989-pretos-ou-pardos-estao-maisescolarizados-mas-desigualdade-em-relacao-aos-brancos-permanece. Acesso em: $10 \mathrm{dez}$. 2019.

LEITE, Patrícia Soares. O Brasil e a cooperação Sul-Sul em três momentos de política externa: os governos Jânio Quadros/João Goulart, Ernesto Geisel e Luiz Inácio Lula da Silva. Brasília: Fundação Alexandre de Gusmão, 2011.

MALOMALO, Bas'llele; LOURAU, Julie; SOUZA, Osmaria Rosa. A UNILAB na perspectiva da cooperação Sul-Sul : uma análise crítica decolonial africana. Cadernos do CEAS, Salvador/Recife, n. 245, p. 517-552, set./dez., 2018. Disponível em: https://cadernosdoceas.ucsal.br/index.php/cadernosdoceas/article/view/454/405. Acesso em: 10 dez. 2019.

MUNANGA, Kabengele. Rediscutindo a mestiçagem no Brasil: identidade nacional versus identidade negra. Belo Horizonte: Autêntica, 2008.

PINTO, Jeremias Pereira; SILVA, Julie Sarah Lourau Alves da. Uma crítica sobre o racismo científico, o mito da democracia racial e apresentação de um novo olhar sobre racismo no Brasil. In: SEMANA DE MOBILIZAÇÃO CIENTÍFICA - SEMOC, 22, Salvador, 2019. Anais [...]. Salvador: UCSAL, 2019. Disponível em: http://ri.ucsal.br:8o8o/jspui/bitstream/prefix/1279/1/uma crítica sobre o racismo científico, o mito da democracia racial e apresentação de um novo olhar sobre racismo no brasil.pdf. Acesso em: 10 nov. 2019. [no prelo].

PIOVESAN, Flávia. Ações Afirmativas sob a Perspectiva dos Direitos Humanos. SANTOS. Sales Augusto dos (Org.). Ações Afirmativas e Combate ao Racismo nas Américas. 
Brasília: Ministério da Educação/ UNESCO, 2005. p. 35-45. Disponível em: http://etnicoracial.mec.gov.br/images/pdf/publicacoes/acoes_afirm_combate_racismo_am ericas.pdf. Acesso em: 02 dez. 2019.

SANTOS, Celso José dos. O Estatuto da Igualdade Racial - Avanços, limites e potencialidades. Cadernos de Educação, Brasília, n. 23, p. 147-163, jul./dez. 2010.

Disponível em: https://www.sinprodf.org.br/wp-content/uploads/2015/02/01-o-estatuto-daigualdade-racial.pdf. Acesso em: 02 dez. 2019.

SCHWARCZ, Lilia Moritz. Espetáculo da miscigenação. Estudos Avançados, São Paulo, v. 8, n. 20, jan./abr. 1994. Disponível em: http://www.scielo.br/pdf/ea/v8n2o/v8n20a17. Acesso em: 05 jun. 2019.

SÃO BERNARDO, Augusto Sérgio. Ética da diferença e criminalização racial. In: Brado Negro. 2005. Disponível em: Acesso em:

http://bradonegro.com/content/arquivo/12122018_132500.pdf . 30 nov. 2019.

SILVA, Mateus Lôbo de Aquino Moura e. Casa-grande \& senzala e o mito da democracia racial. ENCONTRO ANUAL DA ANPOCS, 39, 2015, Caxambu-MG. Anais [...]. São Paulo: Anpocs, 2015. Disponível em: https://www.anpocs.com/index.php/papers-39encontro/gt/gt28/9704-casa-grande-e-senzala-e-o-mito-da-democracia-racial/file. Acesso em: 10 jun. 2019.

SODRÉ, Muniz. A verdade seduzida: por um conceito de cultura no Brasil. 3 ed. Rio de Janeiro: $D P \& A, 2005$.

\section{Detalhes dos autores}

Jeremias Pereira Pinto

Doutorando em Políticas Sociais e Cidadania pela Universidade Católica do Salvador. Membro do grupo de pesquisa Antropologia, Fronteiras, Espaços e Cidadania (GP AFEC). E-mail: jeremias.pinto@ucsal.edu.br//jeppinto45@gmail.com Orcid: http://orcid.org/0000-0002-9877-9977

Julie Lourau

Antropóloga, professora do PPG de Políticas sociais e cidadania da Universidade Católica do Salvador. Líder do grupo de pesquisa Antropologia, Fronteiras, Espaços e Cidadania UCSal/CNPq. Desenvolve pesquisas sobre direitos culturais, racismo, branquitude, festas, políticas públicas. Trabalha também perspectivas epistemológicas periféricas. Organizadora da "Semana da África na Bahia" junto com Bas'llele Malomalo (UNILAB), desde 2017; evento de cunho científico e cultural sobre a África e sua diáspora. Autora do livro Fêtes populaires et carnaval: Le commerce de rue en temps de fête à Salvador de Bahia. L'Harmattan. 2016. E-mail: juliesarahba@gmail.com.Orcid: http://orcid.org/oooo-0003-1848-3664. 